\title{
Radical and oxidative pathways in the pyrolysis of a barium propionate-acetate salt
}

\author{
Silvia Rasi ${ }^{1,2}$, Susagna Ricart ${ }^{2}$, Xavier Obradors ${ }^{2}$, Teresa Puig ${ }^{2}$, Pere Roura-Grabulosa ${ }^{1}$ \\ and Jordi Farjas ${ }^{1}$ \\ ${ }^{1}$ University of Girona, Campus Montilivi, Edif. PII, E17003 Girona, Catalonia, Spain \\ ${ }^{2}$ Institut de Ciència de Materials de Barcelona, ICMAB - CSIC, Campus UA Barcelona, E-08193 \\ Bellaterra, Catalonia, Spain
}

*Corresponding author: Silvia Rasi, silvia.rasi@udg.edu; srasi@icmab.es

\begin{abstract}
Film and powder samples from a $\mathrm{BaAc}_{2}$ solution in propionic acid/MeOH were decomposed in different atmospheres and their thermal decomposition was characterized by means of thermogravimetry coupled with evolved gas analysis techniques (TG-FTIR, EGA-MS) and chemical and structural methods (EA, XRD, FTIR). The thermal behavior of the films was found to be different than the corresponding powder, in terms of volatiles, kinetics, intermediate phases and purity of final product. The mixed Ba-Prop-Ac salt obtained from solution decomposes to $\mathrm{BaCO}_{3}$ before $400^{\circ} \mathrm{C}$ through oxidative degradation, and above $400^{\circ} \mathrm{C}$ in inert atmosphere through a radical path releasing symmetrical ketones. Its double melting behavior is also highlighted and its decomposition understood by comparison with $\mathrm{BaProp}_{2}$ and $\mathrm{BaAc}_{2}$ precursors, and put into context of $\mathrm{YBa}_{2} \mathrm{Cu}_{3} \mathrm{O}_{7-\partial}$ (YBCO) film pyrolysis.
\end{abstract}

Keywords: barium propionate; barium acetate; thermal analysis; TG-FTIR; double melting; pyrolysis;

\section{Introduction}

Barium propionate $\left(\mathrm{Ba}\left(\mathrm{CH}_{3} \mathrm{CH}_{2} \mathrm{CO}_{2}\right)_{2}, \mathrm{BaProp} 2\right)$ and barium acetate $\left(\mathrm{Ba}\left(\mathrm{CH}_{3} \mathrm{CO}_{2}\right)_{2}, \mathrm{BaAc} 2\right)$ find application in the field of ceramic film synthesis through chemical methods, along with similar short chain carboxylate salts of other metals. In particular, they are some of the precursors to $\mathrm{YBa}_{2} \mathrm{Cu}_{3} \mathrm{O}_{7}$ ә (YBCO) [1,2], a high temperature superconductor, obtained from fluorine-free (FF) [3-6] and low fluorine [7] chemical methods. In fact, there are different precursor solutions for the synthesis of YBCO, which, classified with respect to the fluorine content in the metalorganic salt [8], can either be FF (fluorine-free), low fluorine [7] or all fluorine (TFA, trifluoroacetate route) [9-11]. In particular, the latter is a well-known route which permitted to overcome [12] the problem of $\mathrm{BaCO}_{3}$ formation as an undesired intermediate coming from pyrolysis of FF precursors like acetates and propionates [3-6].

In fact, $\mathrm{BaCO}_{3}$ is a challenge for the epitaxial growth of $\mathrm{YBCO}$ due to the fact that its decomposition overlaps with the YBCO crystallization process, making it hard to optimize the growth conditions to obtain epitaxial YBCO films $[3,13]$. On the other hand, the TFA route presents two drawbacks: (i) being not environmentally friendly due to HF (hydrofluoric acid) formation, which in turn requires difficult furnace designs [14] and (ii) low yields, especially for thick films, due to the slow HF out-diffusion during $\mathrm{BaF}_{2}$ decomposition. Conversely, the acknowledgement that it is 
possible to achieve very high growth rates with the FF route thanks to the fact that a liquid Ba-Cu$\mathrm{O}$ phase is formed from $\mathrm{BaCO}_{3}$ decomposition [5] has restored the interest in FF-YBCO as a costeffective chemical solution deposition route (CSD) [15] to replace the more expensive industrial physical methods. Nevertheless, to open up chemical methods to the industry, an optimization of the CSD thermal treatments (pyrolysis and growth) through the study of the thermal behavior of metalorganic precursors is of fundamental interest [16-20].

Regarding the thermal decomposition of BaProp 2 , It has already been demonstrated through evolved gas analysis (EGA) that carboxylate salts of $M(I I)$ and $M(I I I)$ tend to decompose in inert atmosphere releasing a symmetrical ketone as major product, following a radical path of decomposition [20-24]. This however has been found to be affected by the metal center redox behavior, and therefore it does not hold in the case of those carboxylates whose metal easily undergoes redox reactions, like $\mathrm{Cu}$ or $\mathrm{Ag}$ [25-27], for which the main volatile consists of the corresponding acid. According to [28], the salt obtained from the acetate precursor in propionic acid and methanol results in a mixed acetate-propionate complex. By coupling mass spectrometry to thermogravimetry (TG-MS) it is shown that during decomposition in air it releases $\mathrm{CO}_{2}$ in a first small $(\approx 3 \%)$ mass loss, followed by 3-pentanone $(\mathrm{m} / \mathrm{z}=57), \mathrm{CO}_{2}(\mathrm{~m} / \mathrm{z}=44)$ and acetone $(\mathrm{m} / \mathrm{z}=43$ and 58$)$ to yield $\mathrm{BaCO}_{3}$. Previously, it was also reported that barium propionate synthesized from the corresponding carbonate in excess of propionic acid, decomposes in inert atmosphere in two steps [29] of similar mass loss, yielding 3-pentanone and traces of acetone, but no $\mathrm{CO}_{2}$, in accordance with the stoichiometry of the reaction mechanism. Similarly, $\mathrm{BaAc}_{2}$ was shown to decompose to $\mathrm{BaCO}_{3}$, passing through an intermediate barium oxalate stable until $330^{\circ} \mathrm{C}$ [30].

However, so far, the thermal decomposition of barium propionate and barium acetate has been studied only for samples in the form of powder and the volatiles observed only through EGAMS; in fact, only a few studies for FF and fluorine precursors [12,31] can be found for films [32,33]. What happens during the actual pyrolysis of thin films of $\mathrm{BaProp}_{2}$ or $\mathrm{BaAc}_{2}$ has never been seen yet, due to the limiting amount of sample used for films. Additionally, the acetate-propionate equilibrium of barium precursor solution has never been explored in the context of YBCO pyrolysis. We will show that thermal analysis of BaProp $_{2} / \mathrm{Ba}$-Prop-Ac film samples is possible to achieve, and that the Ba carboxylate salt formed in solution depends on the solution history; complementary techniques (TG-FTIR and EGA-MS) have been used to confirm decomposition reactions and volatiles. Solid phases have been characterized by means of Elemental Analysis (EA), X-ray diffraction (XRD) and Fourier Transform Infrared Spectroscopy (FTIR). We will also show that decomposition reactions depend on the atmosphere and sample geometry (film versus powder) [34] resulting in different decomposition paths, showing some similarities with YProp 3 [35].

\section{Materials and Methods}

The initial solution was obtained dissolving barium acetate ( $\mathrm{BaAc}_{2}$, Sigma Aldrich) in propionic acid (Merck, $\geq 99 \%$ ), kept under sonication until complete dissolution of the salt. Then methanol (VWR, $\geq 99.8 \%$ ) was added in order to obtain a mixture of 1:1 in solvent composition and $\mathrm{a}\left[\mathrm{Ba}^{2+}\right]=0.5 \mathrm{M}$. Film samples were obtained depositing the initial solution on $\mathrm{LaAlO}_{3}(\mathrm{LAO})$ substrates and drying them at $95^{\circ} \mathrm{C}$ for a few minutes. The film thickness $(\mathrm{H})$ was estimated with the following equation: $H=m /(d \cdot A)$, where $m$ is the mass of the $\mathrm{BaCO}_{3}$ film after decomposition, $d$ is the $\mathrm{BaCO}_{3}$ particle density, and $A$ is the surface area of the substrate. The powder sample was obtained by drying the corresponding solution at $95^{\circ} \mathrm{C}$. Over a few-month time, a single-crystal was formed in the stored solution, it was recovered and dried in low vacuum (635 $\mathrm{mmHg}$ ) prior to analysis (see supp. Info). A powder obtained from an acetate-free solution (reacting $\mathrm{BaCO}_{3}$ with propionic acid) 
was also prepared for comparison. Both powders (and to a lesser extent films, due to the drying stage prior to the TG analysis) showed residual propionic acid and water up to $\sim 190^{\circ} \mathrm{C}$, and after their complete evaporation the colorless gel becomes a white powder. Since this stage does not affect decomposition, for the main purposes of this work, dehydration is not discussed.

Initial, intermediate and final products of decomposition were characterized by means of FTIR, XRD and EA. Infrared spectra were obtained with a FTIR spectrometer from Bruker ALPHA, connected to an attenuated total reflectance module; EA was performed with a Perkin Elmer 2400 elemental analyzer with the following detection limits: $0,20 \%$ for $\mathrm{H} ; 0,72 \%$ for $\mathrm{C}$. $\mathrm{X}$-ray diffraction measurements of films and powders were run using a D8 ADVANCE diffractometer from Bruker AXS, producing an X-ray beam wavelength of $1.5406 \AA$ ( $\mathrm{Cu}-\mathrm{K} \alpha)$ and with a voltage of $40 \mathrm{kV}$ and a $40-\mathrm{mA}$ current. Single-crystal XRD measurements were carried out at $50 \mathrm{kV}$ and $20 \mathrm{~mA}$ in a three-circle diffractometer by Bruker (D8 QUEST ECO); the system was equipped with a PHOTON II detector (CPAD) and a doubly curved silicon crystal monochromator, and operated with a Mo K $\alpha(\lambda=0.71076$ Å) $x$-ray source.

The volatiles and mass loss for the thermal decomposition of films and powders were studied by means of TG-EGA coupled techniques. Thermogravimetry (TG) was performed with a Mettler Toledo thermo-balance, model TGA/DSC1 for both films on LAO and powders in 70- $\mu$ l open alumina pans. For experiments run in $\mathrm{O}_{2}$, a gas flow of $55 \mathrm{ml} / \mathrm{min}$ was used for the reactive gas, with 15 $\mathrm{ml} / \mathrm{min}$ of protective gas (air); for $\mathrm{N}_{2}$ atmospheres, only the protective gas was used with flows of $70 \mathrm{ml} / \mathrm{min}$. TG-FTIR was obtained by connecting the TGA gas outlet to a FTIR Gas Analyzer (Bruker ALPHA, transmission model) by means of a $40-\mathrm{cm}$ steel tube heated up to $200^{\circ} \mathrm{C}$. EGA-MS experiments were carried out in a quartz tube inserted in a low-resistance furnace and directly connected to an MKS Microvision Plus quadrupole mass analyzer (MS-Q), in vacuum. A rotative pump in series with a turbomolecular pump allowed for the achievement of the required vacuum (which in the sample chamber reached between $10^{-7}$ and $10^{-6}$ bar of total pressure).

Several TG-EGA experiments were conducted varying the sample geometry (film or powder) and the atmosphere. Only when distinction between humid and dry atmosphere is relevant for discussion, it will be specified. Films were decomposed in oxygen (dry and humid, A), in nitrogen (dry and humid, B), and in vacuum (C). The volatiles were detected by TG-FTIR (in A-B) and EGA-MS (in C). The corresponding experiments for powder samples are indicated with a prime symbol as follows: in $\mathrm{O}_{2}\left(\mathbf{A}^{\prime}\right)$, nitrogen ( $\left.\mathbf{B}^{\prime}\right)$ and vacuum $\left(\mathbf{C}^{\prime}\right)$, and studied by means of TG-FTIR and EGA-MS ( $\left.\mathbf{C}^{\prime}\right)$. TG-EGA experiments relative to the $\mathrm{BaProp}_{2}$ and $\mathrm{BaAC}_{2}$ precursors are reported in the Supp. Info.

\section{Results}

\subsection{Characterization of the initial product}

The elemental analysis results of the powder obtained from the $\mathrm{BaAc}_{2}$ precursor solution and from an acetate-free $\left(\mathrm{BaCO}_{3}\right)$ precursor solution are shown in Table 1 . For the latter, the values are in agreement with $\mathrm{BaProp}_{2}$ formation. Conversely, the product obtained from the $\mathrm{BaAc}_{2}$ solution shows a $\mathrm{C}$ and $\mathrm{H} \%$ inferior to the theoretical value for the full replacement of acetates by propionates, indicating that some acetate ligands remain in the structure. In fact, the FTIR spectrum of the dry film in Fig.1 shows the appearance of the $-\mathrm{CH}_{2}$ propionate bands, but the small contribution at 930 and $648 \mathrm{~cm}^{-1}$ (C-C stretching and COO deformation [36], Fig. S2) indicates the presence of acetate groups; the XRD on a single crystal (shown in the Supp. Info) confirms the specie to be a mixed carboxylate with structure $\mathrm{Ba}_{7} \operatorname{Prop}_{8} \mathrm{Ac}_{6} \cdot 4 \mathrm{H}_{2} \mathrm{O}$, similar to what proposed by [28]. The carboxylate ligands are bound in bridging fashion to the $\mathrm{Ba}$ ions, in agreement with the small 
distance between the asymmetric and symmetric stretching of the $\mathrm{COO}^{-}$bond [37-41]: $\Delta \mathrm{v}=\mathrm{V}_{\mathrm{as}}\left(\mathrm{COO}^{-}\right.$ )$-v_{s}\left(\mathrm{COO}^{-}\right)=120.7 \mathrm{~cm}^{-1}$. In particular, three Ba atoms have coordination number 9 and one Ba 8; Fig. $\mathrm{S} 1$ (in supplementary) shows the unit cell where $\mathrm{Ba}(1)$ is surrounded by two $\mathrm{H}_{2} \mathrm{O}$ molecules and four carboxylate groups in bidentate bridging coordination; $\mathrm{Ba}(2)$ is bound to one propionate and one acetate group in bidentate bridging mode; $\mathrm{Ba}(3)$ is coordinated by two ligands in bidentate bridging mode and by one carboxylate in tridentate chelating bridging with $\mathrm{Ba}(4)$. One might expect the ratio propionates/acetates to vary as a function of concentration and solvents ratio. In fact, decreasing $\left[\mathrm{Ba}^{2+}\right]$, the acetate contribution after solution deposition is no longer distinguishable by FTIR; similarly, BaProp 2 is favored in a solution of only propionic acid. Additionally, the powderdiffraction obtained from the single-crystal differs slightly from the powder diffraction pattern of the dry film (both in Fig.1, inset), indicating different water amount or even different propionate/acetate ratio between the two, due to the fact that they were generated by different processes, crystallization versus precipitation (solution deposition), respectively.

The mixed carboxylate specie (labelled as "Ba-Prop-Ac") will be the focus of the present work, and its decomposition will be understood in comparison with "BaProp 2 " (from now on indicating the precursor obtained from the $\mathrm{BaCO}_{3}$ solution) and " $\mathrm{BaAc}_{2}$ " (referring throughout the paper to the commercial sample), while further details about their decomposition can be found in the Supp. Info.

\subsection{Powder decomposition}

The mass evolution and the DSC curves for the thermal decomposition of Ba-Prop-Ac as a function of the atmosphere are reported in Fig. $2 a$ and $2 b$, respectively. For comparison, the evolution of $\mathrm{BaProp}_{2}$ and $\mathrm{BaAc}_{2}$ in humid $\mathrm{O}_{2}$ as film is reported in the same graph, while their thermal behavior as powder can be found in Fig S9 (Supp. Info).

In inert atmosphere $\left(B^{\prime}, \mathrm{N}_{2}\right), B a-P r o p-A c$ as powder is stable up to $400^{\circ} \mathrm{C}$. Before $400^{\circ} \mathrm{C}$, only two small endothermic peaks are observed (Fig.2) at $230^{\circ} \mathrm{C}$ and $380^{\circ} \mathrm{C}$, which indicate that melting occurred (additionally confirmed by repeating the experiment under visual observation for the low peak temperature). Although normally two melting peaks are interpreted as arising from two different phases in the sample, the same two peaks are also observed for the pure BaProp 2 (although shifted in temperature, see Fig.2). For a pure substance, this feature has been explained in terms of recrystallization effects [42], where the first peak is representative of continuous melting and recrystallization into a different solid phase with higher melting temperature, and has also been observed for other barium carboxylates [43]. When performing two consecutive heating ramps up to $280^{\circ} \mathrm{C}$, at the second ramp the low-temperature melting disappears while the one at $380^{\circ} \mathrm{C}$ remains (see Supp. Info, Fig. S3c). A general shift of the XRD peaks to lower $2 \theta$ is observed after heating to $280^{\circ} \mathrm{C}$, after dehydration and the first endothermic peak have taken place (Fig. S3, S4 in Supplementary). Decomposition starts above $400^{\circ} \mathrm{C}$ : Ba-Prop-Ac decomposes following the radical decomposition path that is common in carboxylates [20,22-24], releasing symmetrical ketones to form $\mathrm{BaCO}_{3}$ (inset in Fig.1) between 450 and $500^{\circ} \mathrm{C}$. Among these ketones, the main volatile is 3pentanone $\left(\mathrm{C}_{2} \mathrm{H}_{5} \mathrm{COC}_{2} \mathrm{H}_{5}\right.$, Fig.3) coming from the propionate ligands and, in less extent, acetone $\left(\mathrm{CH}_{3} \mathrm{COCH}_{3}\right)$, coming from the acetate part. Since there is an excess of propionate groups with respect to the acetate ones, the main contribution comes from the 3-pentanone. In fact, BaProp 2 follows a similar decomposition path with similar resulting volatiles in $\mathrm{N}_{2}$ (see Supp. Info, Fig.S6), which is represented by reaction scheme $\boldsymbol{\beta}$ in Fig.4. No $\mathrm{CO}_{2}$ is detected, as expected from the stoichiometry of reaction, indicating that no other reaction paths are competing with $\boldsymbol{\beta}$. Below $1000^{\circ} \mathrm{C}$, neither $\mathrm{BaO}$ nor $\mathrm{BaO}_{2}$ are expected to form. In addition to the XRD results, the thermogravimetric analysis in Fig. 2 shows the corresponding TG final mass $(72.0 \%)$ to be in 
agreement with $\mathrm{BaCO}_{3}$ formation (expected: $69.6-72.7 \%$ for $\mathrm{BaProp}_{2}$ and $\mathrm{Ba}_{7} \mathrm{Prop}_{8} \mathrm{Ac}_{6}$, respectively) and the elemental analysis results (EA in Table.1) confirm the presence of $C$ in the sample, with complete removal of all hydrogen atoms. However, the final product is not white (as expected for $\mathrm{BaCO}_{3}$ ), but gray, suggesting that some carbon residue may be left in the sample up to $600^{\circ} \mathrm{C}$. If the dark color were due to sub-stoichiometry of oxygen, we would expect the mass to increase upon further heating of the sample in oxygen. However, when the latter is re-heated in $\mathrm{O}_{2}$ up to $700^{\circ} \mathrm{C}$, the mass slightly decreases and the final color is white (and the FTIR spectrum still confirms the presence of $\mathrm{BaCO}_{3}$ ). Therefore, the black color could be assigned to carbon residue left in the sample upon decomposition in inert atmosphere.

In oxygen (both humid and dry, $\mathbf{A}^{\prime}$ ), decomposition of powders starts earlier (around $310^{\circ} \mathrm{C}$ ) and involves two steps. The first step consists of oxidative exothermic reactions (denoted as reaction scheme $\alpha$ in Fig.2 and Fig.4) and will be described in the following section. The second step takes place in the same temperature range as the radical mechanism previously described. Thus, two mechanisms compete: when the oxidative decomposition is slowed down by the slow gas diffusion in the powder, oxidation of the ligand is not complete so that the remaining salt continues decomposing following the radical path as the temperature increases. But 3-pentanone is not observed in a nominal atmosphere of $\mathrm{O}_{2}$ (or humid $\mathrm{O}_{2}$ ) suggesting that the radicals $\mathrm{C}_{2} \mathrm{H}_{5} \mathrm{CO} \cdot / \mathrm{C}_{2} \mathrm{H}_{5}$. do not recombine. In fact, the $\mathrm{O}_{2}$ can drive oxidation of $\mathrm{C}_{2} \mathrm{H}_{5} \mathrm{CO}$ to $\mathrm{CO}_{2}$ while the alkyl groups are converted to ethane $\left(\mathrm{C}_{2} \mathrm{H}_{4}\right)$ and ethylene $\left(\mathrm{C}_{2} \mathrm{H}_{6}\right)$ (Fig.3 $A^{\prime}$ and reaction scheme $\boldsymbol{\gamma}$ in Fig.4). In $\mathrm{O}_{2}$ ( $A^{\prime}$ in Fig.2b) the DSC signal is, in fact, more exothermic than in $\mathrm{N}_{2}$ ( $\mathbf{B}^{\prime}$ in Fig.2b). BaProp decomposes $_{2}$ following the same path (details in Supp. Info, Fig. S7), and for this reason the contribution of the acetate part is not considered in Fig.4.

\subsection{Film decomposition}

\section{Decomposition in oxidative atmosphere}

The mixed Ba carboxylate films are stable until $200-230^{\circ} \mathrm{C}$ (Fig.2a), the exact temperature depending on film thickness (Fig.6). Then, in both humid and dry $\mathrm{O}_{2}$ (A), decomposition starts roughly in correspondence of the first melting peak. Independently of the fact that several sudden changes in the TG curve appear as the thickness increases (Fig.6) which will be discussed later on, decomposition in oxygen is mainly driven by oxidation, as suggested by the DSC exothermic peak (Fig.2b). As shown in Fig.3a and 3b, several reactions overlap as the $\mathrm{C}-\mathrm{C}$ chain is oxidized first to acetaldehyde $\left(\mathrm{CH}_{3} \mathrm{CHO}\right)$ and $\mathrm{CO}_{2}$, and then further decomposed to methane $\left(\mathrm{CH}_{4}\right)$ and $\mathrm{CO}$. In dry and humid $\mathrm{O}_{2}$, the decomposition shows similar behavior: water does not seem to accelerate decomposition, contrarily to other propionates [35,44], and the volatiles do not differ from the dry $\mathrm{O}_{2}$ case, as no propionic acid can be detected. Even for thin films (see Fig.6), the final product consists of $\mathrm{BaCO}_{3}$, even in the presence of water vapor.

The infrared spectra of the solid residues (Fig.5) show that before yielding the final product $\mathrm{BaCO}_{3}$, formation of an oxalate occurs, as the $\mathrm{COO}^{-}$stretching band shifts above $1580 \mathrm{~cm}^{-1}$ [45]. It is not uncommon for metal carboxylates to yield intermediate oxalates, oxycarbonates and carbonates before decomposing to the oxide. For the barium case, formation of the oxalate follows from the retainment of the carbonyl groups of the salt while the latter experiences cleavage of the $\mathrm{BaOC}(=\mathrm{O})-\mathrm{R}$ bond during the oxidative degradation, which is in agreement with the difficulty to break the $\mathrm{BaO}-\mathrm{C}(=\mathrm{O}) \mathrm{R}$ bond to yield the oxide at such low temperatures. The oxalate is not a stable intermediate and, as soon as it is formed, it decomposes to $\mathrm{BaCO}_{3}$ already around $330-350^{\circ} \mathrm{C} \mathrm{(Fig.5).}$ To confirm the presence of the oxalate, a sample quenched in humid $\mathrm{O}_{2}$ at $340^{\circ} \mathrm{C}$ (Supp. Info, Fig.S11) was decomposed in vacuum, yielding $\mathrm{CO}_{2}$ as main volatile. Although $\mathrm{CO}$ is expected for $\mathrm{BaC}_{2} \mathrm{O}_{4}$ decomposition to yield $\mathrm{BaCO}_{3}$, the dark color of the final product indicates the presence of 
carbon that can be attributed to disproportion of $\mathrm{CO}$ to $\mathrm{C}+\mathrm{CO}_{2}[46,47]$. In fact, the final product is grayish/black already for 6-7 $\mu \mathrm{m}$ where the slow local out-diffusion of the CO enhances CO disproportion; only thinner films $(\sim 2 \mu \mathrm{m})$ are white due to the faster $\mathrm{CO}$ out-diffusion with respect to its production. After $350^{\circ} \mathrm{C}$, as the $\mathrm{BaCO}_{3}$ is formed, decomposition slows down and it is not complete until $450^{\circ} \mathrm{C}$, when the mass is stable at $\sim 71 \%$ (Fig.6). Fig. $3 \mathrm{~A}$ shows that $\mathrm{CO}_{2}$ alone is detected by gas-IR above $400^{\circ} \mathrm{C}$. To clarify if the mass loss at this stage is due to the oxalate decomposition (expected final mass for $\mathrm{BaC}_{2} \mathrm{O}_{4}$ formation starting from $\mathrm{BaProp}_{2}$ and $\mathrm{Ba}_{7} \mathrm{Prop}_{8} \mathrm{Ac}_{6}$ : 79.5\%-83.0\%, respectively) or to the acetate part (expected final mass for the removal of all propionates in $\mathrm{Ba}_{7} \mathrm{Prop}_{8} \mathrm{Ac}_{6}: 81.9 \%$ ), Ba-Prop-Ac TG curves can be compared with those of BaProp 2 and $\mathrm{BaAc}_{2}$ (Fig.2). The Ba-Prop-Ac salt curve measured in $\mathrm{O}_{2}$ is closer to that of $\mathrm{BaProp}_{2}$ than to that of $\mathrm{BaAc}_{2}$, which decomposes $\sim 100^{\circ} \mathrm{C}$ above (dotted lines in Fig.2). The BaProp $\mathrm{B}_{2}$ salt exhibits the same volatiles as $\mathrm{Ba}_{7} \mathrm{Prop}_{8} \mathrm{Ac}_{6}$ in oxygen (humid and dry, see Fig S5), the only difference being that it decomposes to $\mathrm{BaCO}_{3}$ in a single mass-loss step at $\sim 350^{\circ} \mathrm{C}$ during which the oxalate $\left(\mathrm{BaC}_{2} \mathrm{O}_{4}\right)$ is still formed (detected by FTIR while it converts to $\mathrm{BaCO}_{3}$, Fig.S13). This suggests that the mass loss step above $350^{\circ} \mathrm{C}$ in the mixed carboxylate salt is not due to the oxalate decomposition but to the decomposition of the acetate part of the salt, in agreement with the higher decomposition temperature of $\mathrm{BaAc}_{2}$. This effect is shown in Fig.6 where, as the Ba-Prop-Ac film thickness increases, decomposition slows down after $350^{\circ} \mathrm{C}$. The effect seems to be more important in humid than in dry $\mathrm{O}_{2}$, probably because $\mathrm{O}_{2}$ concentration and thus its diffusion rate through the film is lower in the presence of water vapor, hence oxidation is slowed down. As a further proof, Fig.S11 shows that the same quenched sample at $340^{\circ} \mathrm{C}$ yields mainly $\mathrm{m} / \mathrm{z}=43$ (acetone) upon further decomposition, due to the remaining barium acetate, while the contribution of propionate groups is residual. The XRD results in Fig.1 (inset) show that the final product is the orthorhombic phase of $\mathrm{BaCO}_{3}$ at $500^{\circ} \mathrm{C}$, as expected $[48,49]$.

As introduced above, decomposition in $\mathrm{O}_{2}$ shows the presence of several sudden changes in the slope of the TG curve (Fig.6) with increasing film thickness. The abrupt mass loss at $330-340^{\circ} \mathrm{C}$ is probably caused by the fast $\mathrm{O}_{2}$ diffusion through the liquid as soon as Ba-Prop-Ac melts. Afterwards, above $350^{\circ} \mathrm{C}$, formation of $\mathrm{BaCO}_{3}$ slows down gas diffusion again. Although the second melting event is expected to occur at a higher temperature than those of the fast mass loss, it can shift due to the presence of decomposition products generated by the early reaction of $\mathrm{O}_{2}$ with the sample surface. In fact, this discontinuity of the TG curve at $\sim 340^{\circ} \mathrm{C}$ is characteristic of both films and powders, showing no thermal activation changing the heating rates (Fig. 6 , curve at $20^{\circ} \mathrm{C} / \mathrm{min}$ ).

\section{Decomposition in $\mathrm{N}_{2}$ atmosphere}

When the film is decomposed in nominally humid and dry $\mathrm{N}_{2}(C)$, the behavior differs from the powder sample in $\mathrm{N}_{2}\left(\mathbf{B}^{\prime}\right)$ and resembles that of powders in $\mathrm{O}_{2}\left(\mathbf{A}^{\prime}\right)$ : reaction $\boldsymbol{\alpha}$ and reactions $\boldsymbol{\beta}$ and $\boldsymbol{\gamma}$ take place at low and high temperature, respectively. In fact, decomposition is triggered at the discontinuity in the TG curve at $330^{\circ} \mathrm{C}$ generated by the melting event; this first step between 320 and $380^{\circ} \mathrm{C}$ becomes more important with decreasing film thickness (Fig.S8) and, therefore, it can be ascribed to residual oxygen content in the nominally oxygen-free atmosphere; in fact it has already been shown that the thinner the film, the more prone to oxidize $[35,50]$. During this stage, $\mathrm{CO}_{2}$ is detected by TG-FTIR, along with acetaldehyde and propionic acid (Fig.S8). In fact, since $\mathrm{O}_{2}$ is residual, it is not enough to get full oxidation (reaction $\boldsymbol{\alpha}$ ) and partial oxidation takes place [44] according to:

$$
\mathrm{Ba}\left(\mathrm{C}_{2} \mathrm{H}_{5} \mathrm{CO}_{2}\right)_{2}+\mathrm{O}_{2} \rightarrow \mathrm{CH}_{3} \mathrm{CHO}+\mathrm{C}_{2} \mathrm{H}_{5} \mathrm{CO}_{2} \mathrm{H}+\mathrm{BaCO}_{3} .
$$

As the $\mathrm{BaCO}_{3}$ is formed (see Fig.5B), it acts as a diffusion barrier to $\mathrm{O}_{2}$, and oxidation cannot reach completion. Thus, a second step at a higher temperature (between $400-470^{\circ} \mathrm{C}$ ) occurs. Reaction 
schemes $\boldsymbol{\beta}$ (favored in $\mathrm{N}_{2}$ ) and $\boldsymbol{\gamma}$ (triggered by $\mathrm{O}_{2}$ ) compete. Given the fact that the volatiles evolve during a longer period of time than in $\mathrm{O}_{2}$ atmosphere, they become more diluted and, consequently, their TG-IR signal is smaller; nevertheless $\mathrm{CO}_{2}$ (related to $\gamma$ ) could be clearly detected. The last mass loss between $470-530^{\circ} \mathrm{C}$, which corresponds again to $\mathrm{CO}_{2}$ release, is due to decomposition of the acetate part (See Fig.S7 and S8). For this reason, Fig.3A' reports the TG-FTIR analysis of powders in $\mathrm{O}_{2}$, since they follow a similar trend. The overall decomposition behavior of films in nominally inert atmosphere can be interpreted as a mix of decomposition in an oxidizing atmosphere and in inert atmosphere (reaction $\boldsymbol{\beta}$ ). Note that the DSC signal in Fig. $2 \mathrm{~b}$ is always exothermic.

\section{Decomposition in vacuum}

Since residual oxygen is extremely low in vacuum, only in these conditions $\mathrm{CO}_{2}$ is not detected for films (Fig.3C). The main fragments are $\mathrm{m} / \mathrm{z}=57,29$ (coming from 3-pentanone) along with $\mathrm{C}_{2} \mathrm{H}_{x}$ fractions of the ligand $(\mathrm{m} / \mathrm{z}=29,28,27)$. A very similar behavior is observed in vacuum for BaProp $_{2}$ (see Supp. Info, Fig.S10), for which the same volatiles are detected, including $\mathrm{m} / \mathrm{z}=43$. This last fragment could be $\mathrm{CH}_{3} \mathrm{CO}$ or $\mathrm{C}_{3} \mathrm{H}_{7}$, coming from acetone or from butane, respectively. However, since in this particular case no acetate groups are present, $\mathrm{m} / \mathrm{z}=43$ can be ascribed to butane formation, according to reaction scheme $\partial$ of Fig.4. This interpretation can also explain part of the $\mathrm{m} / \mathrm{z}=43$ coming from the Ba-Prop-Ac decomposition in vacuum (E), indicating that the main component in the mixed carboxylate salt is still made up of propionates, thus justifying again the reaction schemes of Fig.4. Interestingly, in vacuum decomposition is shifted down by almost $100^{\circ} \mathrm{C}$ with respect to the case of inert atmosphere at atmospheric pressure (dry $N_{2}, B^{\prime}$ ), although they both proceed through the radical path. This early decomposition is probably triggered by the barium carboxylate (second peak) melting, which is shifted to lower temperatures as the pressure decreases.

\section{Discussion}

BaProp $_{2}$ and Ba-Prop-Ac decomposition is diffusion-controlled: in an oxidizing atmosphere, films decompose at a temperature lower than powders due to the faster gas exchange [32,33,35], which helps the low-temperature decomposition mechanism triggered by oxygen. Unlike the YProp 3 case, a humid atmosphere does not clearly accelerate decomposition through the hydrolysis of the salt (and propionic acid release), since this reaction path would require formation of the oxide and not the oxalate-carbonate sequence of products. Besides that, $\mathrm{BaProp}_{2}$ thermal decomposition seems to follows the expected radical mechanism at high temperatures and inert atmospheres already found for YProp 3 [35] and for those carboxylate salts where the metal center does not easily undergo reduction [25] . In fact, local residual oxygen depletion around the sample in the form of powder suppresses the oxidative reaction in a nominally inert $\mathrm{N}_{2}$ atmosphere. In contrast, films in this atmosphere are affected by the residual oxygen content and, as it occurs in $\mathrm{O}_{2}$, they decompose at a temperature lower than powders. The Ba-Prop-Ac thermogravimetric behavior in films is less smooth with respect to that of other metalorganic precursors $[35,44]$ because it is disrupted by the melting events. $\mathrm{O}_{2}$ diffusion is accelerated in the melt, while any solid decomposition product (oxalate and carbonate) slows down gas diffusion. Only a study as a function of thickness has revealed this dependence, which could be otherwise mistaken for intermediates.

The presence of acetaldehyde among the volatiles of this work cannot necessarily be related to the presence of acetate ligands in the salt [28], since acetaldehyde was also detected among the gaseous products of the BaProp 2 salt [29]. In fact, although the crystal consists of a mixed propionate-acetate complex, the thermal behavior of the solution and the powder in all 
atmospheres tends to that of $\mathrm{BaProp}_{2}$, in terms of kinetics and volatiles, and the presence of acetate ligands is hard to detect from EGA alone. It is thus possible that the Prop/Ac ratio of the crystal (obtained from a long aging of the solution) differs slightly from that of the dry solution (used for film and powder decomposition). In fact, the final mass is always inferior to the expected $72.7 \%$ for the $\mathrm{Ba}_{7} \mathrm{Prop}_{8} \mathrm{Ac}_{6}-\mathrm{BaCO}_{3}$ conversion which, counting the presence of residual carbon and the instrumental error (especially in films due to the small amount of material), points towards a slightly higher Prop/Ac ratio.

Our results can be significant to understand FF-YBCO film pyrolysis. In particular, the propionate/acetate ratio in the ternary solution is also expected to depend on concentration and solvents ratio. The presence of other acetate salts (i.e. those of $\mathrm{Cu}$ and $\mathrm{Y}$ ) in solution can further alter this equilibrium and, eventually, favor formation of the mixed carboxylate complex. If this complex is formed instead of $\mathrm{BaProp}_{2}$, decomposition of thick films in $\mathrm{O}_{2}$ would end at higher temperatures. Although $\mathrm{BaCO}_{3}$ constitutes a challenge for the epitaxial growth of $\mathrm{FF}-\mathrm{YBCO}$, in the conditions of this work and for the isolated barium precursor, no specific case was found were a carbonated product can be avoided in favor of a hydroxide or an oxide, not even in humid atmospheres.

\section{Conclusions}

The thermal decomposition of BaProp 2 was studied as a function of sample geometry (films and powders) and the atmosphere (inert or oxidizing). It has been found that decomposition is enhanced in oxidizing with respect to inert conditions, but not much in a humid atmosphere. Like many carboxylates, the radical mechanism with 3-pentanone formation prevails at high temperatures and inert conditions but, unlike other carboxylates where the oxide is formed, the low temperature mechanism is favored by oxidation and not by hydrolysis. Therefore, even in humid atmospheres, no hydroxides nor oxides are formed at $500^{\circ} \mathrm{C}$. Decomposition is also diffusioncontrolled, and hence faster for thinner films and for films in general with respect to powders. This fact can be explained by the different gas diffusion between surface and bulk. Additionally, the presence of melting events affects decomposition, because gas diffusion in a liquid phase is faster than in a solid. For films up to a few $\mu \mathrm{m}$ decomposition is over by $500^{\circ} \mathrm{C}$, but for films thicker than 3-6 $\mu \mathrm{m}$, carbon residues are left on the sample. Finally, in the context of FF-YBCO pyrolysis, the final decomposition temperature for thick films is expected to depend on the barium species in solution, in particular, on the acetate to propionate ratio.

\section{Acknowledgments}

This work was funded by Ministerio de Ciencia, Innovación y Universidades (grant numbers RTI2018095853-B-C21 and RTI2018-095853-B-C22); it was also supported by the Center of Excellence Severo Ochoa (SEV-2015-0496) and the Generalitat of Catalunya (2017-SGR-1519). SR wishes to thank the University of Girona for the IF-UdG PhD grant; all authors wish to thank the UdG and ICMAB (Institut de Ciència de Materials de Barcelona) for their scientific services. 


\section{References}

[1] D.M. de Leeuw, C.A.H.A. Mutsaers, R.A. Steeman, E. Frikkee, H.W. Zandbergen, Crystal Structure and Electrical Conductivity of YBa4Cu308.5+d, Phys. C. 158 (1989) 391-396.

[2] A. Rahman, Z. Rahaman, N. Samsuddoha, A Review on Cuprate Based Superconducting Materials Including Characteristics and Applications, Am. J. Phys. Appl. 3 (2015) 39-56. doi:10.11648/j.ajpa.20150302.15.

[3] P. Vermeir, I. Cardinael, J. Schaubroeck, K. Verbeken, B. Michael, P. Lommens, W. Knaepen, D. Jan, K. De Buysser, I. Van Driessche, Elucidation of the Mechanism in Fluorine-Free Prepared YBa2Cu307- $\delta$ Coatings, Inorg. Chem. 49 (2010) 4471-4477. doi:10.1021/ic9021799.

[4] M. Nasui, T. Petrisor, R.B. Mos, M.S. Gabor, A. Mesaros, F. Goga, L. Ciontea, T. Petrisor, Fluorine-free propionate route for the chemical solution deposition of YBa2Cu3O7- $\mathrm{x}$ superconducting films, Ceram. Int. 41 (2015) 4416-4421. doi:10.1016/j.ceramint.2014.11.132.

[5] L. Soler, et al., Ultrafast transient liquid assisted growth of high current density superconducting films, Nat. Mater. (n.d.) submitted.

[6] Y. Zhao, P. Torres, X. Tang, P. Norby, J. Grivel, Growth of Highly Epitaxial YBa2Cu3O7- $\delta$ Films from a Simple Propionate-Based Solution, Inorg. Chem. 54 (2015) 10232-10238. doi:10.1021/acs.inorgchem.5b01486.

[7] X. Palmer, C. Pop, H. Eloussi, B. Villarejo, P. Roura, J. Farjas, A. Calleja, A. Palau, T. Puig, S. Ricart, Solution design for low-fluorine trifluoroacetate route to $\mathrm{YBa} 2 \mathrm{Cu} 3 \mathrm{O} 7 \mathrm{films}$, Supercond. Sci. Technol. 29 (2016) 24002. doi:10.1088/0953-2048/29/2/024002.

[8] D.E. Wesolowski, Y.R. Patta, M.J. Cima, Conversion behavior comparison of TFA-MOD and non-fluorine solution-deposited YBCO films, Phys. C Supercond. Its Appl. 469 (2009) 766773. doi:10.1016/j.physc.2009.04.008.

[9] V. Solovyov, I.K. Dimitrov, Q. Li, Growth of thick YBa2Cu3O7 layers via a barium fluoride process, Supercond. Sci. Technol. 26 (2013) 13001-13020. doi:10.1088/09532048/26/1/013001.

[10] A. Gupta, R. Jagannathan, E.I. Cooper, E.A. Giess, J.I. Landman, B.W. Hussey, Superconducting oxide films with high transition temperature prepared from metal trifluoroacetate precursors, Appl. Phys. Lett. 52 (1998) 2077-2079. doi:10.1063/1.99752.

[11] X. Obradors, T. Puig, S. Ricart, M. Coll, J. Gazquez, A. Palau, X. Granados, Growth , nanostructure and vortex pinning in superconducting $\mathrm{YBa} 2 \mathrm{Cu} 3 \mathrm{O} 7$ thin films based on trifluoroacetate solutions, Supercond. Sci. Technol. 25 (2012) 123001. doi:10.1088/09532048/25/12/123001.

[12] H. Eloussifi, J. Farjas, P. Roura, S. Ricart, T. Puig, X. Obradors, M. Dammak, Thermal decomposition of barium trifluoroacetate thin films, Thermochim. Acta. 556 (2013) 58-62. doi:10.1016/j.tca.2013.01.022.

[13] P. Vermeir, J. Feys, J. Schaubroeck, K. Verbeken, P. Lommens, I. Van Driessche, Influence of sintering conditions in the preparation of acetate-based fluorine-free CSD YBCO films using a direct sintering method, Mater. Res. Bull. 47 (2012) 4376-4382. doi:10.1016/j.materresbull.2012.09.033.

[14] T. Araki, I. Hirabayashi, Review of a chemical approach to YBa2Cu3O7-x -coated superconductors - metalorganic deposition using trifluoroacetates, Supercond. Sci. Technol. 16 (2003) 71-94. doi:10.1088/0953-2048/16/11/r01.

[15] X. Obradors, T. Puig, M. Gibert, A. Queraltó, J. Zabaleta, N. Mestres, Chemical solution route 
to self-assembled epitaxial oxide nanostructures, Chem. Soc. Rev. 43 (2014) 2200-2225. doi:10.1039/c3cs60365b.

[16] R.M. Escovar, J.H. Thurston, T. Ould-ely, A. Kumar, K.H. Whitmire, Synthesis and Characterization of New Mono-, Di-, and Trinuclear Copper(II) Triethanolamine-Carboxylate Complexes, Z. Anorg. Allg. Chem. 631 (2005) 2867-2876. doi:10.1002/zaac.200500204.

[17] M. Yoshizumi, I. Seleznev, M.J. Cima, Reactions of oxyfluoride precursors for the preparation of barium yttrium cuprate films, Phys. C. 403 (2004) 191-199. doi:10.1016/j.physc.2003.12.004.

[18] L. Ciontea, A. Angrisani, G. Celentano, T. Petrisor jr., A. Rufoloni, A. Vannozzi, A. Augieri, V. Galuzzi, A. Mancini, T. Petrisor, Metal propionate synthesis of epitaxial YBa2Cu3O7-x films, J. Phys. Conf. Ser. 97 (2008) 12302. doi:10.1088/1742-6596/97/1/012302.

[19] Z. Lin, D. Han, S. Li, Study on thermal decomposition of copper(II) acetate monohydrate in air, J. Therm. Anal. Calorim. 107 (2012) 471-475. doi:10.1007/s10973-011-1454-4.

[20] J.-C.C. Grivel, Thermal decomposition of yttrium(III) propionate and butyrate, J. Anal. Appl. Pyrolysis. 101 (2013) 185-192. doi:10.1016/j.jaap.2013.01.011.

[21] M. Nasui, T. Petrisor Jr, R.B. Mos, A. Mesaros, R.A. Varga, B.S. Vasile, T. Ristoiu, L. Ciontea, T. Petrisor, Synthesis, crystal structure and thermal decomposition kinetics of yttrium propionate, J. Anal. Appl. Pyrolysis. 106 (2014) 92-98. doi:10.1016/j.jaap.2014.01.004.

[22] J. Grivel, Thermal decomposition of $\mathrm{Ln}(\mathrm{C} 2 \mathrm{H} 5 \mathrm{CO} 2) 3 \bullet \mathrm{H} 2 \mathrm{O}(\mathrm{Ln}=\mathrm{Ho}, \mathrm{Er}$, Tm and $\mathrm{Yb})$, J. Therm. Anal. Calorim. 109 (2012) 81-88. doi:10.1007/s10973-011-1745-9.

[23] J. Grivel, Thermal decomposition of lutetium propionate, J. Anal. Appl. Pyrolysis. 89 (2010) 250-254. doi:10.1016/j.jaap.2010.08.011.

[24] M. Nasui, C. Bogatan (Pop), L. Ciontea, T. Petrisor, Synthesis, crystal structure modeling and thermal decomposition of yttrium propionate $[\mathrm{Y} 2(\mathrm{CH} 3 \mathrm{CH} 2 \mathrm{COO}) 6 \cdot \mathrm{H} 2 \mathrm{O}] \cdot 3.5 \mathrm{H} 2 \mathrm{O}$, J. Anal. Appl. Pyrolysis. 97 (2012) 88-93. doi:10.1016/j.jaap.2012.05.003.

[25] M.S. Akanni, E.K. Okoh, H.D. Burrows, H.A. Ellis, The thermal behaviour of divalent and higher valent metal soaps : a review, Thermochim. Acta. 208 (1992) 1-41. doi:10.1016/0040-6031(92)80150-u.

[26] M.S. Akanni, H.D. Burrows, P.B. Begun, Product analysis, reaction mechanism and kinetics of the thermal decomposition of some even chain-length mercury(II) carboxylates, Termochimica Acta. 81 (1984) 45-58. doi:10.1016/0040-6031(84)85109-6.

[27] M.S. Akanni, O.B. Ajayi, J.N. Lambi, Pyrolytic Decomposition of Some Even Chain Length Copper(II) Carboxylates, J. Therm. Anal. 31 (1986) 131-143. doi:10.1007/bf01913894.

[28] R.B. Mos, M. Nasui, T. Petrisor Jr, M.S. Gabor, R. Varga, L. Ciontea, T. Petrisor, Synthesis, crystal structure and thermal decomposition study of a new barium acetato-propionate complex, J. Anal. Appl. Pyrolysis. 92 (2011) 445-449. doi:10.1016/j.jaap.2011.08.007.

[29] L.D.S. Mindrale, U.C. Bernard--, Comportement Thermique des Propionates Hydrates de Calcium, Strontium et Baryum, J. Therm. Anal. 12 (1977) 33-42. doi:10.1007/bf01909853.

[30] U. Hwang, H. Park, K. Koo, Behavior of Barium Acetate and Titanium Isopropoxide during the Formation of Crystalline Barium Titanate, Ind. Eng. Chem. Res. 43 (2004) 728-734. doi:10.1021/ie030276q.

[31] H. Eloussi, J. Farjas, P. Roura, S. Ricart, T. Puig, X. Obradors, M. Dammak, Thermoanalytical study of the decomposition of yttrium trifluoroacetate thin films, Thin Solid Films. 545 (2013) 200-204. doi:10.1016/j.tsf.2013.07.082.

[32] D. Sanchez-rodriguez, J. Farjas, P. Roura, S. Ricart, N. Mestres, X. Obradors, T. Puig, Thermal Analysis for Low Temperature Synthesis of Oxide Thin Films from Chemical Solutions, J. Phys. Chem. C. 117 (2013) 20133-20138. doi:10.1021/jp4049742.

[33] P. Roura, J. Farjas, H. Eloussi, L. Carreras, S. Ricart, T. Puig, X. Obradors, Thermal analysis of 
metal organic precursors for functional oxide preparation: Thin films versus powders, Thermochim. Acta. 601 (2015) 1-8. doi:10.1016/j.tca.2014.12.016.

[34] J. Farjas, D. Sanchez-Rodriguez, H. Eloussifi, R.C. Hidalgo, P. Roura, S. Ricart, T. Puig, X. Obradors, Can we trust on the thermal analysis of metal organic powders for thin film preparation?, in: M. Jain, X. Obradors, Q. Jia, R.W. Schwartz (Eds.), Solut. Synth. Inorg. Film. Nanostructured Mater., MRS Procee, MRS Warrendale, 2012: pp. 13-18. doi:10.1557/opl.2012.919.

[35] S. Rasi, S. Ricart, X. Obradors, T. Puig, P. Roura, J. Farjas, Thermal decomposition of yttrium propionate: film and powder, J. Anal. Appl. Pyrolysis. 133 (2018) 225-233. doi:10.1016/j.jaap.2018.03.021.

[36] K. Ito, H.J. Bernstein, The vibrational spectra of the formate, acetate, and oxalate ions, Can. J. Chem. 34 (1956) 170-178. doi:10.1139/v56-021.

[37] R. Urlaub, U. Posset, R. Thull, FT-IR spectroscopic investigations on sol-gel-derived coatings from acid-modified titanium alkoxides, J. Non-Cyrstalline Solids. 265 (2000) 276-284. doi:10.1016/s0022-3093(00)00003-x.

[38] S. Doeuff, M. Henry, C. Sanchez, J. Livage, Hydrolysis of titanium alkoxides: modification of the molecular precursor by acetic acid, J. Non-Cyrstalline Solids. 9 (1987) 206-216. doi:10.1016/s0022-3093(87)80333-2.

[39] V. Zeleňák, Z. Vargová, K. Györyová, Correlation of infrared spectra of zinc(II) carboxylates with their structures, Spectrochim. Acta Part A Mol. Biomol. Spectrosc. 66 (2007) 262-272. doi:10.1016/j.saa.2006.02.050.

[40] K. Nakamoto, Y. Morimoto, A.E. Martell, Infrared Spectra of Metal Chelate Compounds. IV. Infrared Spectra of Addition Compounds of Metallic Acetylacetonates 1a, J. Am. Chem. Soc. 83 (1961) 4533-4536. doi:10.1021/ja01483a010.

[41] G. Deacon, Relationships between the carbon-oxygen stretching frequencies of carboxylato complexes and the type of carboxylate coordination, Coord. Chem. Rev. 33 (1980) 227-250. doi:10.1016/S0010-8545(00)80455-5.

[42] D.J. Blundell, On the interpretation of multiple melting peaks in poly (ether ether ketone), Polymer (Guildf). 28 (1987) 2248-2251. doi:10.1016/0032-3861(87)90382-x.

[43] P. Torres, P. Norby, J. Grivel, Thermal decomposition of barium valerate in argon, J. Anal. Appl. Pyrolysis 116. 116 (2015) 120-128. doi:10.1016/j.jaap.2015.09.018.

[44] S. Rasi, F. Silveri, S. Ricart, X. Obradors, T. Puig, P. Roura-Grabulosa, J. Farjas, Thermal decomposition of CuProp2: In-situ analysis of film and powder pyrolysis, J. Anal. Appl. Pyrolysis. 140 (2019) 312-320. doi:10.1016/j.jaap.2019.04.008.

[45] M.M. Torres, D. Palacios, C.D. María, A.C. González-baró, E.J. Baran, Vibrational spectra of barium oxalate hemihydrate, Spectrosc. Lett. 49 (2016) 238-240. doi:10.1080/00387010.2015.1133651.

[46] A.H. Verdonk, A. Broersma, Thermal Decomposition of Barium Oxalate Hemihydrate BaC2O4•0.5H2O, Thermochim. Acta. 6 (1973) 95-110. doi:10.1016/0040-6031(73)80009-7.

[47] D. Dollimore, The thermal decomposition of oxalates. A review, Thermochim. Acta. 117 (1987) 331-363. doi:10.1016/0040-6031(87)88127-3.

[48] J. Chaney, J.D. Santillán, E. Knittle, Q. Williams, A high-pressure infrared and Raman spectroscopic study of BaCO3: the aragonite, trigonal and Pmmn structures, Phys. Chem. Miner. 42 (2015) 83-93. doi:10.1007/s00269-014-0702-0.

[49] S.M. Antao, I. Hassan, $\mathrm{BaCO} 3$ : high-temperature crystal structures and the Pmcn-->R3m phase transition at $811^{\circ} \mathrm{C}$, Phys. Chem. Miner. 34 (2007) 573-580. doi:10.1007/s00269007-0172-8.

[50] P. Roura, J. Farjas, S. Ricart, M. Aklalouch, R. Guzman, J. Arbiol, T. Puig, A. Calleja, O. Peña- 
Rodríguez, M. Garriga, X. Obradors, Synthesis of nanocrystalline ceria thin films by lowtemperature thermal decomposition of Ce-propionate, Thin Solid Films. 520 (2012) 19491953. doi:10.1016/j.tsf.2011.09.058. 


\section{Figure captions}

Fig.1: Infrared spectra of the initial product obtained after solution deposition and (inset) X-ray diffraction patterns of the phase evolution from decomposition in $\mathrm{O}_{2}(\mathbf{A} / \mathbf{B})$. Inset: $(\bullet) \mathrm{BaCO}_{3}$ from ICSD 15196, PDF 45-1471; bottom, filled spectrum: powder diffraction of a $\mathrm{Ba}_{7} \mathrm{Prop}_{8} \mathrm{Ac}_{6} \cdot 4 \mathrm{H}_{2} \mathrm{O}$ crystal (obtained from a crystallization process) for comparison with the powder diffraction pattern of the dry film (obtained from deposition/precipitation process).

Fig.2: Thermal decomposition of Ba-Prop-Ac film and powder in different atmospheres at 5K/min: a) TG curves and b) corresponding DSC signal, with enlargement in inset comparing the DSC signal of $\mathrm{BaProp}_{2}$ and Ba-Prop-Ac in $\mathrm{N}_{2}$. Dotted lines: TG curves of the $\mathrm{BaProp}_{2}$ and $\mathrm{BaAc}_{2}$ precursors in humid $\mathrm{O}_{2}$ at $5 \mathrm{~K} / \mathrm{min}$ as film. Horizontal lines: expected mass for decomposition of Ba-Prop-Ac into $\mathrm{BaC}_{2} \mathrm{O}_{4}$ and $\mathrm{BaCO}_{3}$.

Fig.3: a) TG-FTIR and EGA-MS results for Ba-Prop-Ac powder and film, at 5K/min. b) corresponding FTIR spectra of the volatiles during decomposition (at 330,350 and $490^{\circ} \mathbf{C}$ for $\mathbf{A}, \mathbf{A}^{\prime}$ and $\mathbf{B}^{\prime}$, respectively).

Fig.4: Proposed decomposition reactions for BaProp 2 .

Fig.5: Infrared evolution of the solid residue at different decomposition temperatures; $\left({ }^{\circ}\right)$ Ba-Prop$\mathrm{Ac},(\bullet) \mathrm{BaCO}_{3},(\boldsymbol{\Delta})$ Barium Oxalate $\left(\mathrm{BaC}_{2} \mathrm{O}_{4}\right)$.

Fig.6: TG curves of Ba-Prop-Ac in humid $\mathrm{O}_{2}$, showing the effect of thickness on the decomposition temperature: the thicker the film, the slower the $\mathrm{O}_{2}$ diffusion. The TG curves of the films are compared to those of the powder samples.

\section{Tables}

\begin{tabular}{|c|c|c|}
\hline \multirow{2}{*}{ Compound } & \multicolumn{2}{|c|}{ Found (Expected) } \\
\hline & $\% \mathrm{C}$ & $\% \mathrm{H}$ \\
\hline $\mathrm{BaProp}_{2}$ (from $\mathrm{BaCO}_{3}$ ) & $25.3(25.42)$ & $3.5(3.56)$ \\
\hline Ba-Prop-Ac (from BaAc ${ }_{2}$ ) & 23.1 & 3.4 \\
\hline A film in hum. $\mathrm{O}_{2}\left(600^{\circ} \mathrm{C}\right)$ & $6.3(6.09)$ & - \\
\hline 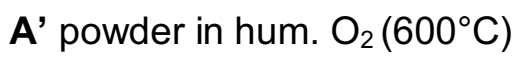 & $6.4(6.09)$ & - \\
\hline
\end{tabular}

Table 1. Elemental analysis of initial and final compounds obtained from film and powder decomposition; (-) values inferior to detection limits 


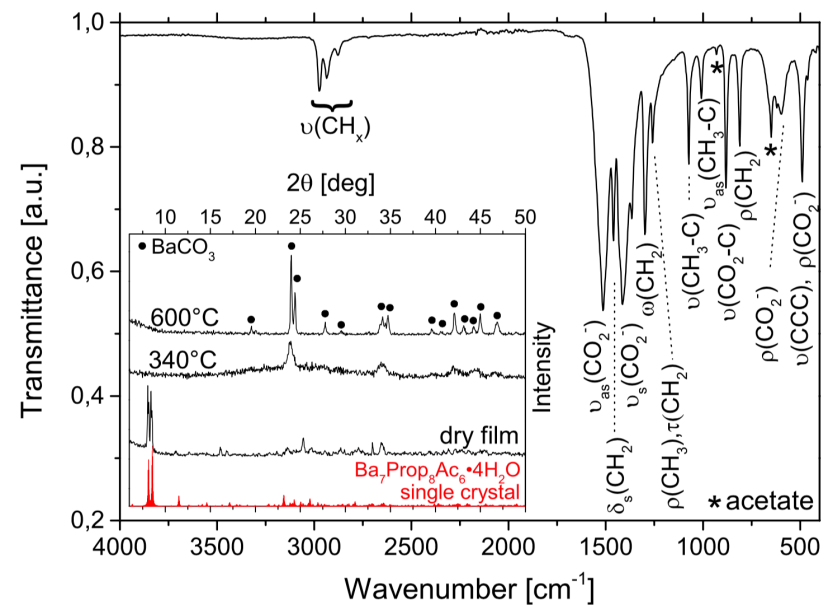

Fig. 1

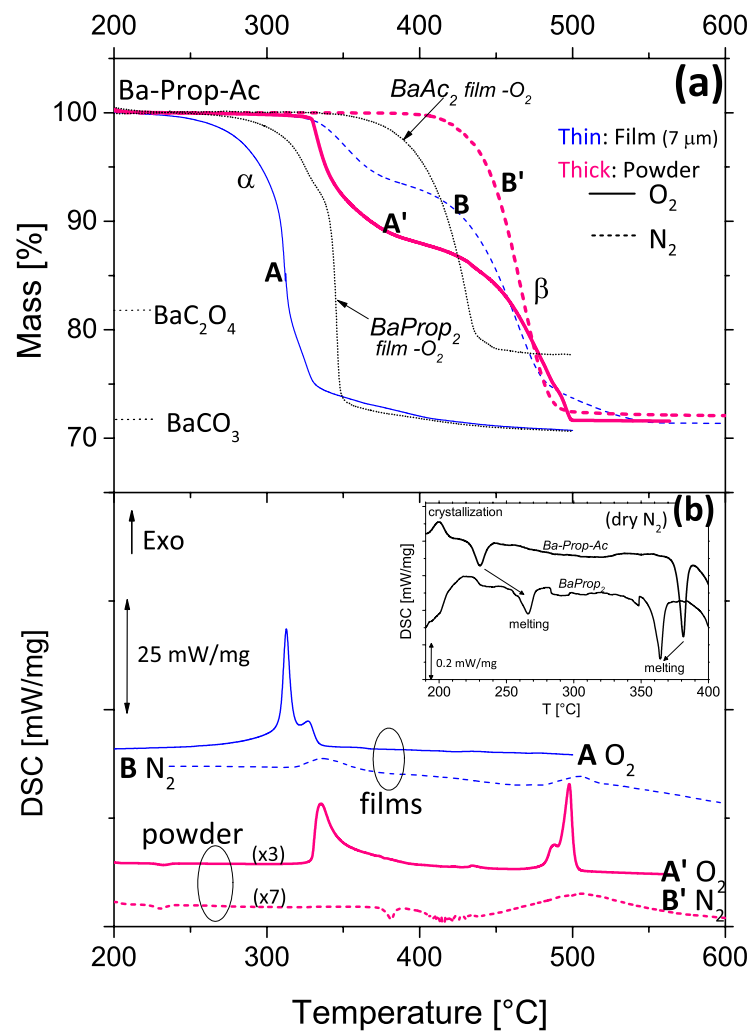

Fig. 2

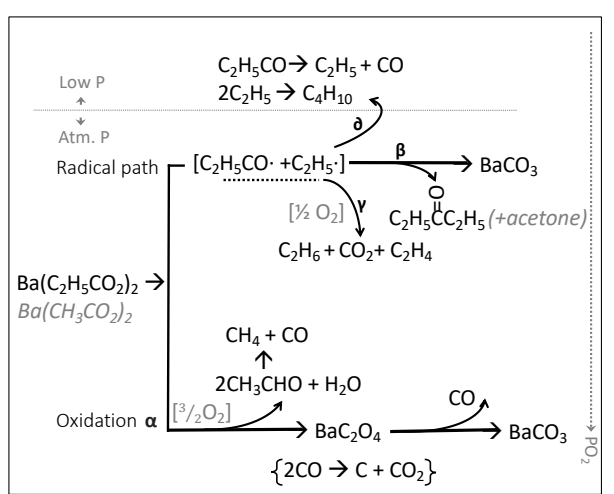

Fig. 4 

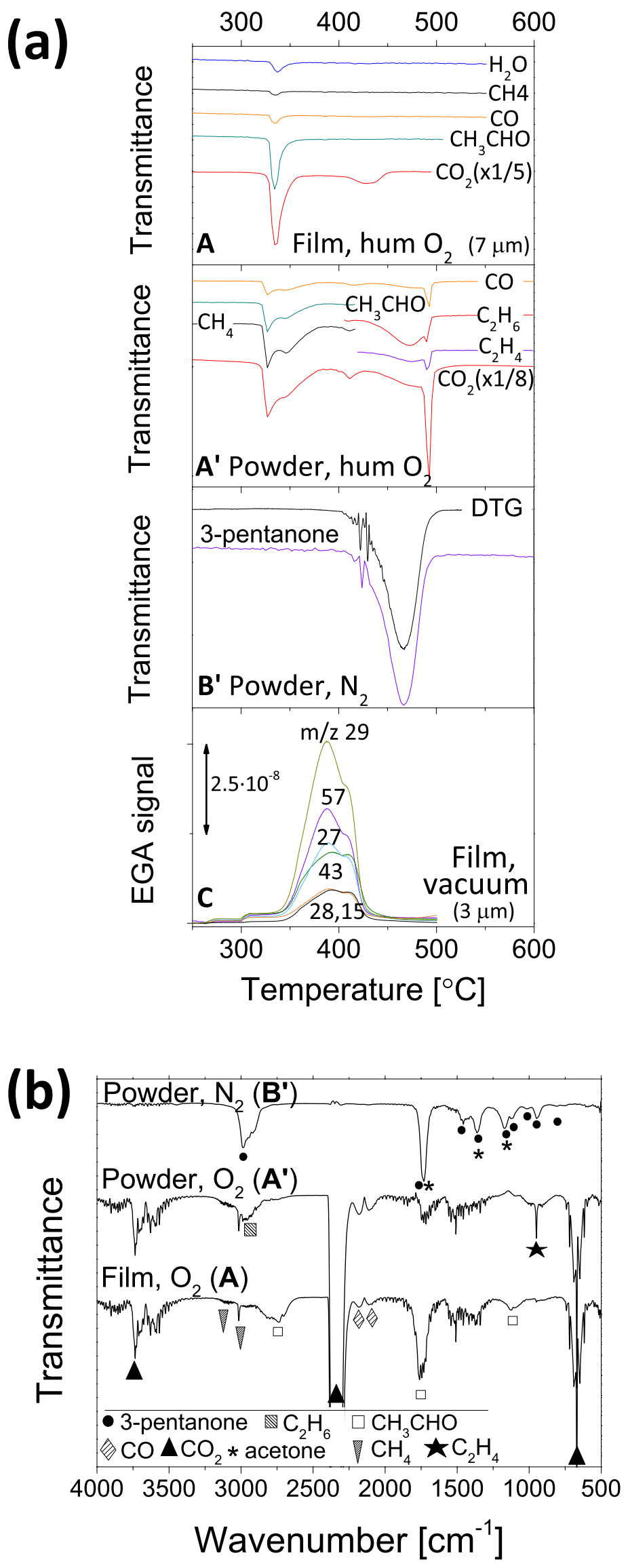

Fig. 3 

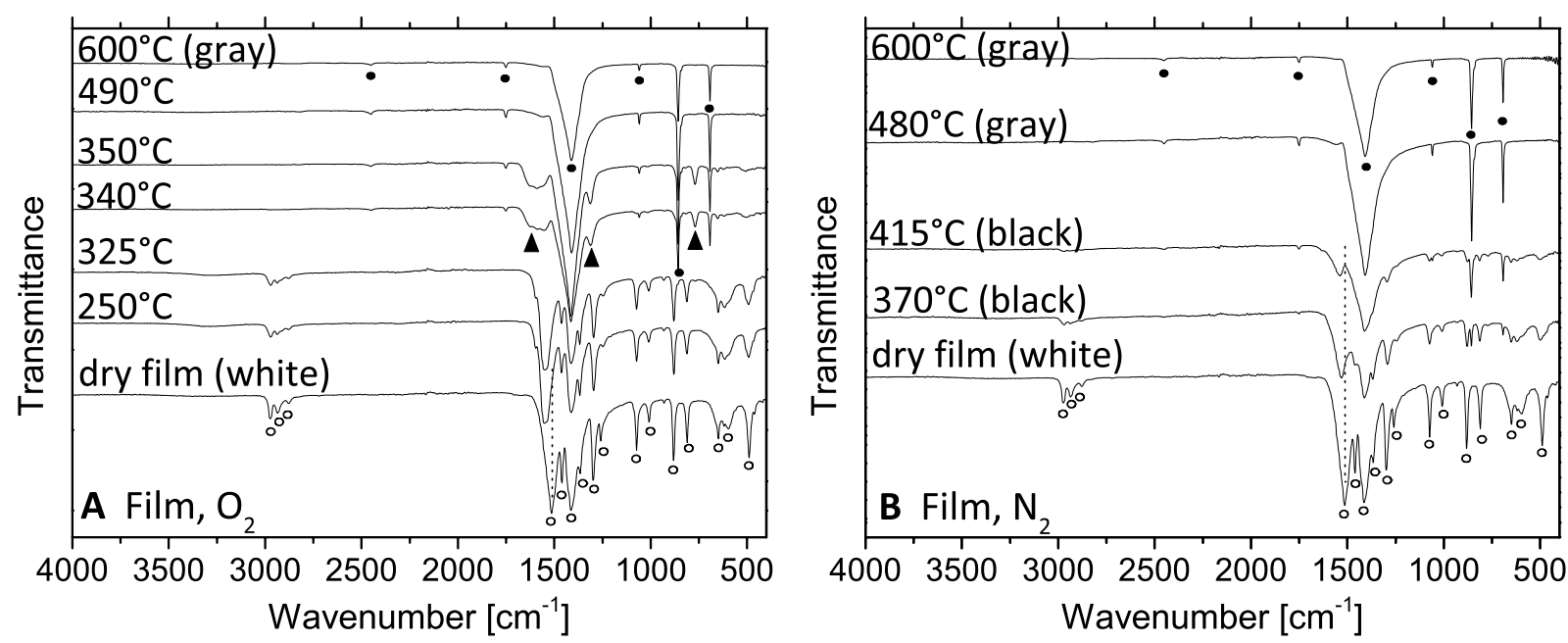

Fig. 5

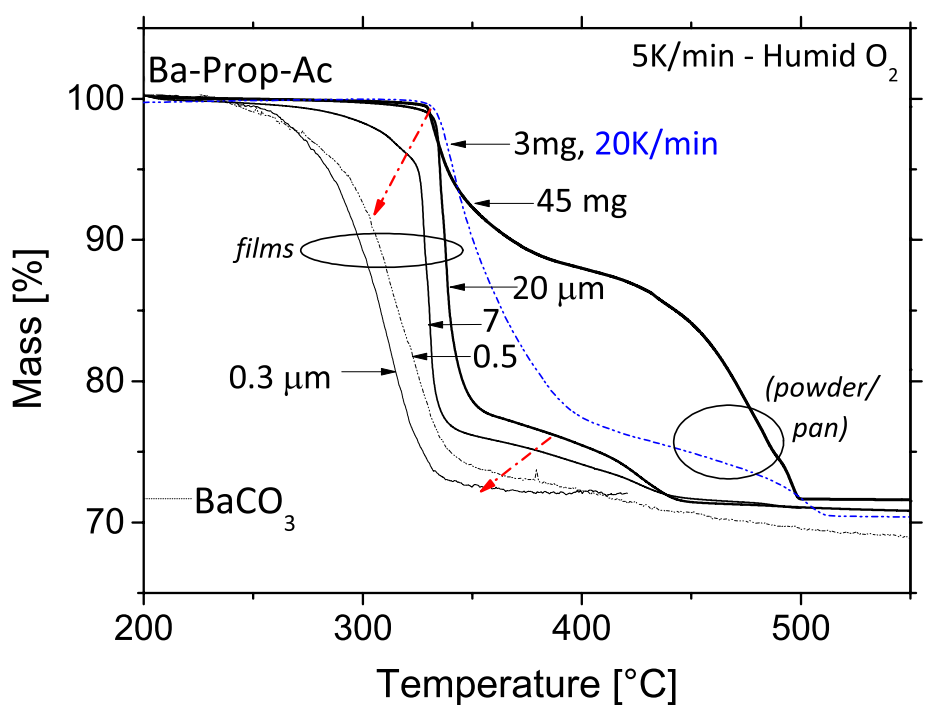

Fig. 6 